\title{
Integrated care in mental health: next steps after the NHS Long Term Plan
}

Derek K. Tracy, Kara Hanson, Tom Brown, Adrian J. B. James, Holly Paulsen, Zoé Mulliez and Sukhwinder S. Shergill

\section{Summary}

Health and social care face growing and conflicting pressures: mounting complex needs of an ageing population, restricted funding and a workforce recruitment and retention crisis. In response, in the UK the NHS Long Term Plan promises increased investment and an emphasis on better 'integrated' care. We describe key aspects of integration that need addressing.

\section{Declaration of interest}

D.K.T. and S.S.S. are on the editorial board of the British Journal of Psychiatry and executives of the Academic Faculty at the Royal College of Psychiatrists. A.J.B.J., H.P. and Z.M. have roles at the
Royal College of Psychiatrists that include evaluation of integrated care systems. A.J.B.J. is married to Dr Sarah Wollaston, Member of Parliament for Totnes and Chair of the Health Select committee.

\section{Keywords}

Integrated care; NHS Long Term Plan; ICS; integrated care system.

\section{Copyright and usage}

(C) The Royal College of Psychiatrists 2019.
Derek K. Tracy (pictured) is a Consultant Psychiatrist and Clinical Director at Oxleas NHS Foundation Trust, a Senior Lecturer at the Institute of Psychiatry, Psychology and Neuroscience, King's College London and an Honorary Senior Lecturer in the Department of Psychiatry, University College London. Kara Hanson is Professor of Health System Economics and the Dean of the Faculty of Public Health and Policy at the London School of Hygiene and Tropical Medicine. Tom Brown is Service Director of Bexleycare, Oxleas NHS Foundation Trust and the London Borough of Bexley. Adrian J. B. James is a Consultant Forensic Psychiatrist at Devon Partnership NHS Trust and Registrar of the Royal College of Psychiatrists. Holly Paulsen is Deputy Head of Policy and Campaigns at the Royal College of Psychiatrists. Zoé Mulliez is Policy and Campaigns Manager at the Royal College of Psychiatrists. Sukhwinder S. Shergill is an Honorary Consultant at South London and Maudsley NHS Foundation Trust and Professor of Psychiatry and Systems Neuroscience at the Institute of Psychiatry, Psychology and Neuroscience, King's College London.

\section{Drivers for change}

Integrated care is proposed as a more efficient client-oriented health model, building services around local populations. Drivers include a growing and ageing population with greater comorbidities, as well as workforce and financial challenges. In the UK, the NHS Long Term Plan $^{1}$ is mandating 'integrated care systems' (ICSs) to develop and deliver locally relevant 5 -year plans. Several critical questions remain unanswered: what does 'integration' mean; which services 'should' be integrated; how to win hearts and minds of staff during integration; and how to measure its 'success'? Evaluation cannot be an add-on to becoming an ICS, it must be integral to enable the spread of best practice and learning from failures.

Over the past decade, National Health Service (NHS) funding has grown by about $1 \%$ annually. Approximately $40 \%$ of NHS trusts are reporting deficits, up from less than $10 \%$ in $2009-$ $10 .^{2}$ The NHS Long Term Plan promises $£ 20.5$ billion more by 2023 ( $£ 2.3$ billion for mental health), ${ }^{1}$ a $3.4 \%$ increase, but still below the $4 \%$ recommended to meet demand. ${ }^{2}$ Nevertheless, health has - arguably - always been proportionately better funded and supported than social care, politicians perhaps more averse to the electoral challenges of closing clinical services. Local authorities have suffered spending cuts and social care is, by and large, subject to means testing in contrast to universally free health services. The (delayed) UK governmental Green Paper on social care's long-term future will be as societally important as the NHS Long Term Plan.
By 2035 England's population will have grown by over four million, with a $50 \%$ increase in the over $65 \mathrm{~s}$, and a quadrupling of those with four or more illnesses. The Royal College of Psychiatrists predicts increasing demand across mental health services, most significantly for cognitive impairment and dementia. ${ }^{3}$ Those with multi-morbidities particularly risk care-fragmentation, impaired quality of life, and, unsurprisingly, impose considerably greater health costs. Concluding the gloom, there are approximately 100000 unfilled staff posts in both the NHS and social care, which will double by 2030 given the current trend.

This supply-demand mismatch, which is mirrored internationally, needs greater funding or greater efficiency, one constant refrain being 'more integrated care'. Existing health models largely evolved top-down tracking professional boundaries, whereas this promises a more logical patient-facing design. The emphasis is on prevention, utilising community resources and self-management, with better care for less money through greater efficiencies.

This idea is hardly new, but gained prominence from the 2014 NHS Five Year Forward View. ${ }^{4}$ Sustainability and transformation plans/partnerships (STPs) joined NHS trusts, local authorities and clinical commissioning groups to develop 'place-based' population plans. STPs are anticipated to evolve into ICSs that will strategically plan, commission and manage services, delivered by 'integrated care partnerships/providers' (ICPs) hubbed to primary care population 'footprints' of about 80 000. The NHS Long Term Plan has clearly laid out that 'doing things differently' via ICSs is the way forward. STPs and ICSs are tasked to develop and implement local 5-year integrative plans by autumn 2019. ICP contracts will be available to commissioners by April 2019, and the expectation is that ICSs will cover the UK by April 2021.

\section{The key challenges}

The acronyms are confusing, and there is a lack of clear models and robust evidence. The Royal College of Psychiatrists has expressed concern that mental health has not been sufficiently considered in ICSs, and its amalgamation with overspent acute-sector partners risks cuts to mental health services. Further, we propose there are four major challenges that need to be carefully addressed. 


\section{What does 'integration' mean?}

Details on ICSs and ICPs are intentionally non-prescriptive: encouraging localism and adapting resources to community needs. There have been few examples incorporating mental health; the Royal College of Psychiatrists and the King's Fund noting such opportunities have not yet been maximised. ${ }^{5}$ There is an emphasis on colocation of different services, but the logistical aspects of this are enormous: a simple example is the challenge of seamless integration of different computer systems used in health and social care.

A tripartite framework is needed, covering the nature and degree of integration of: the major organisations of health and social care being integrated; the specific amalgamating teams; and support functions such as finances, information technology, etc (see the Appendix). A standardised matrix would permit organisations to both better understand and describe their model, as well as enable comparison between distinct features and performance of different integrative designs.

\section{Which services 'should' be integrated?}

This speaks to the 'boundary' of an integrated system. For example, should it integrate physical and mental health across primary and secondary settings, as well as social care across the whole local authority? Within mental health one might debate integrating working age and older persons' mental health, child and adolescent services, substance use and so forth. Some services seem to inevitably 'sit above', but work into, integrated care hubs - crisis teams, wards, tertiary interventions - but for many others it is less clear. For example, consider early intervention and rehabilitation psychiatry. In one sense, integrating these with physical health services and the local authority offers considerable potential advantages for longer-term health and social inclusion. Conversely, the reason we have separate services is recognition that 'treatment as usual' misses out some specific needs, and such patients risk getting lost in a wider system.

Without the baggage of history, would one start with specific groups (for example older adults) or services with other complementarities - in the sense that they share a common infrastructure, or some other way of working together? An economist would pose this through the lens of potential economies of scope/scale whether it is less costly to provide things separately or together. Currently, we lack criteria and data with which to make such decisions, and most integration will be a compromise between what is considered optimal and what is achievable.

\section{Winning hearts and minds on the frontline}

We believe that integration will be won or lost by the engagement of frontline staff. It appeals to most patients and senior managers via the drivers of care and efficiencies, but an effective novel system necessitates working in new ways, not just 'more closely with others', with changes in practice that many may find problematic. Existing services have benefits in terms of training, development and peer support; being a smaller part of a bigger and more heterogeneous team poses the risk - speculatively at least - of encouraging generic skill sets at the cost of specialist development, and demoralising an already stretched workforce. It may feel that it is the money driving all change.

One can counter that there will be novel training and practice opportunities in an enriched work environment, and that mental health's biopsychosocial approach is a natural fit for integrative care. In our workforce crisis, new models offer both opportunities and risks.

\section{How will we know if integration is working?}

There is a lack of consensus of how we should evaluate change and know if, and for whom, an integrated model is 'working'. A recent synthesis of measurement tools for integrated health systems identified 114 across 16 domains $^{6}$ - some agreement for ICSs is required. The Medical Research Council has provided guidance on developing and evaluating complex interventions, but there is a need for consensus in determining causal links between changes at the organisational level, and the processes and outcomes experienced by both patients and the staff.

We need to know whether integration improves clinical outcomes, real-life functioning and satisfaction. Needs vary across patients and there is a risk that ICSs emphasise the complex (and expensive) minority of patients requiring multiple inputs to the detriment of the larger number with 'simpler' needs. Indicators could include qualitative data, patient and clinician reported outcome measurements, and patient activation measurements that ask individuals how able they feel to manage their health. However, we lack consensus on which tools to use (including their fitness to describe outcomes in a new model), and, typically, no good 'before' data. At a 'high end' or top of a causal chain, one might explore strategic objectives such as changing suicide rates, life expectancy and employment, although these have the various challenges of (relatively) small numbers and slow change.

With complex organisational changes it is important to track effects on quality, volumes and costs, including the costs of changing the system. There are a range of existing key performance indicators from referral waits, through planned versus unplanned admissions, to delayed transfer of care; from cardiometabolic assessments to flu vaccinations; from complaints to patient experience data and so forth.

There is an absence, to the best of our knowledge, of a healthcare 'staff activation measurement', although demonstrating change in professionals' perceptions of their abilities to manage care is appealing. Qualitative work might again be valuable in identifying appropriate elements of an integration scale and experiences of working in ICSs, as well as the proxy measures of staff and trainee recruitment, satisfaction, sickness and retention.

\section{Next steps}

'Integrated care', as a broad concept, appeals as a seemingly reasoned way for health and social services to deliver better care and manage the wider financial reality. One only has to look at physical health outcomes in those with psychosis, or the links between depression and many chronic health problems and social disadvantage to see the need to do things differently. However, it is determining the underlying detail of what this means that remains crucial, not least what 'integration' really means.

Integrating organisations need frameworks and tools to describe their integration model - and how it will be evaluated. Engaging staff and patients is essential to the process, and a necessary starting point for developing methodologies to evaluate organisational changes and outcomes. Appraising the outcomes of these models, both good and bad, will be necessary to inform rapid and transparent dissemination and scale-up decisions.

Derek K. Tracy, FRCPsych (iD, Consultant Psychiatrist and Clinical Director, Oxleas NHS Foundation Trust; Senior Lecturer, The Institute of Psychiatry, Psychology and Neuroscience, King's College London; and Honorary Senior Lecturer, Department of Psychiatry, University College London, UK; Kara Hanson, SCD, Professor of Health system Economics and Dean, Faculty of Public Health and Policy, the London School of System Economics and Dean, Faculty of Public Health and Policy, the London School of
Hygiene and Tropical Medicine, UK; Tom Brown, PQSW, Service Director, Bexleycare, Oxleas NHS Foundation Trust; and the London Borough of Bexley, UK; Adrian

J. B. James, FRCPsych, Registrar, Royal College of Psychiatrists; and Consultant Forensic Psychiatrist, Devon Partnership NHS Trust, UK; Holly Paulsen, MSC, Deputy Head of Policy and Campaigns, Royal College of Psychiatrists, UK; Zoé Mulliez, MSc, Policy and Campaigns Manager, Royal College of Psychiatrists, UK; Sukhwinder S. Shergill, FRCPsych, Professor of Psychiatry and Systems Neuroscience, Institute of Psychiatry, Psychology and Neuroscience, King's College London; and Honorary Consultant, South London and Maudsley NHS Foundation Trust, UK

Correspondence: Derek Tracy, Queen Mary's Hospital, Sidcup DA14 6LT, UK. Email: derek.tracy@nhs.net

First received 29 Jan 2019, final revision 4 Feb 2019, accepted 9 Feb 2019 


\section{Appendix}

\section{An overview of the areas that should be considered by integrating services}

\begin{tabular}{|c|c|c|c|}
\hline Description of degree of integration & Organisations & Teams (sample list) & Support functions \\
\hline $\begin{array}{l}\text { This will vary by domain and described } \\
\text { organisation/service/support function, but } \\
\text { most crudely might be considered: integrated, } \\
\text { partially/hybrid integration, not integrated/not } \\
\text { included in a model }\end{array}$ & $\begin{array}{l}\text { - } \text { Primary care } \\
\text { - Secondary mental } \\
\text { - } \text { health } \\
\text { - } \text { hecondary physical } \\
\text { - Social care } \\
\text { - Tertiary services } \\
\text { - Voluntary sector }\end{array}$ & $\begin{array}{l}\text { - Adult mental health: community mental health } \\
\text { teams, in-patient wards, crisis teams, substance } \\
\text { use, early-intervention psychosis } \\
\text { - } \text { Older people's mental health: community mental } \\
\text { health teams, memory services } \\
\text { - } \quad \text { Community physical health: district nurses, end- } \\
\text { of-life care, physiotherapy, diabetes, respiratory, } \\
\text { cardiovascular care } \\
\text { - } \quad \text { Adult social care: housing, safe-guarding, public } \\
\text { health, education }\end{array}$ & $\begin{array}{l}\text { - } \text { Finance } \\
\text { - Human resources } \\
\text { - Information } \\
\text { governance } \\
\text { - Estates } \\
\text { - } \text { Management } \\
\text { structure } \\
\text { - Professional } \\
\text { development }\end{array}$ \\
\hline
\end{tabular}

\section{References}

1 NHS England. NHS Long Term Plan. NHS England, 2019 (https://www.england. nhs.uk/long-term-plan/)

2 Institute for Fiscal Studies and The Health Foundation. Securing the Future: Funding Health and Social Care to the 2030s. The Institute for Fiscal Studies, 2018.

3 Royal College of Psychiatrists. NHS Priorities and Reform in Developing a Long-term Plan and Multi-year Funding Settlement for England. The Royal College of Psychiatrists' Proposals for Change. The Royal College of Psychiatrists, 2019
4 NHS England. NHS Five Year Forward View. NHS England, 2014 (https://www. england.nhs.uk/wp-content/uploads/2014/10/5yfv-web.pdf)

5 Naylor C, Taggart H, Charles A. Mental Health and New Models of Care. Lessons Form the Vanguards. The King's Fund and the Royal College of Psychiatrists, 2017

6 Suter E, Oelke ND, da Silva Lima MAD, Stiphout M, Janke R, Witt RR, et al. Indicators and measurement tools for health systems integration: a knowledge synthesis. Int J Integr Care 2017: 17: 4.

\section{Poem}

\section{To a psychiatrist}

\section{Rebecca Lawrence}

To you, I am a brief moment,

A problem, if not solved, then put aside.

My anguish is interesting to you,

But cannot touch you.

To me, you are hope,

You will say the forgotten words

That will mend the frayed thread

of my existence.

Trembling, I wait

For what never comes.

How can you say

What you do not know?

l look into a mirror

And close the sides,

And see green reflections,

Endlessly. 